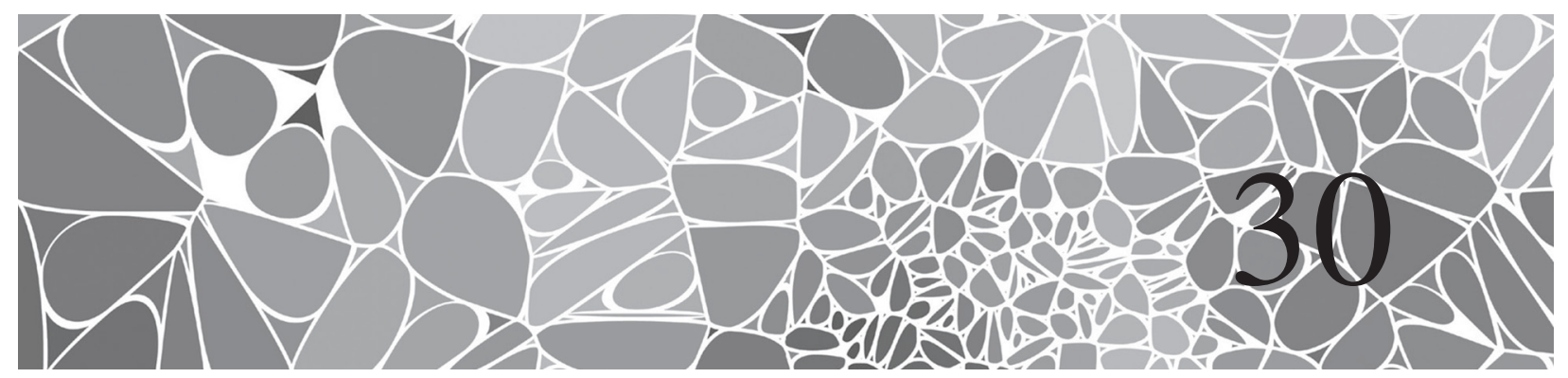

\title{
Youth and Community Approaches to Preventing Child Sexual Exploitation: South African and UK Project Experiences
}

Kate D'Arcy, Roma Thomas and Candice T. Wallace

\section{INTRODUCTION}

This chapter brings together case studies from two pieces of research - an evaluative study in the UK (D'Arcy et al., 2015) and a participatory action research project in South Africa (Wallace, 2015). The chapter aims to provide international perspectives on youth and community approaches to empowering children, young people and their families in preventing and raising awareness of Child Sexual Exploitation (CSE) and Child Sexual Abuse (CSA). It highlights the potential relevance and significance of central tenets of youth and community approaches to prevention work in CSE and CSA by drawing upon the concepts of education, voluntary engagement, participation, strengths-based approaches and rights-based models of working with children and young people.

Both case studies will be used to illustrate community level preventative work. They focus on the innovative methods used to engage children, young people and adults as social actors, collaborators, researchers and change agents, thereby shifting away from didactic approaches of designing programmes and interventions to address the 'problems' of individual young people and families, where there is no consultation or involvement in the process. The two studies: the Families and Communities against Child Sexual Exploitation (FCASE) project in the UK, and the Participatory Approaches to Child Protection (PACP) study in South Africa, together highlight unique perspectives and approaches in addressing CSA (in South Africa) and CSE (in the UK) through young people's participation, education and empowerment. The frequently hidden nature of abuse and stigma are common factors for both CSE and CSA. The authors believe that this underscores the importance of examining the potential benefits of participatory approaches and of community engagement in sexual abuse and sexual exploitation prevention work. Furthermore, these are areas that remain under-explored in the literature. 
Child sexual exploitation is a form of child sexual abuse which occurs where an individual or group takes advantage of an imbalance of power to coerce, manipulate or deceive a child or young person under the age of 18 into sexual activity (a) in exchange for something the victim needs or wants, and/or (b) for the financial advantage or increased status of the perpetrator or facilitator. The victim may have been sexually exploited even if the sexual activity appears consensual. Child sexual exploitation does not always involve physical contact; it can also occur through the use of technology (Department for Education, 2017).

Child sexual abuse is defined according to the World Health Organization (WHO, 1999) as:

... the involvement of a child in sexual activity that he or she does not fully comprehend, is unable to give informed consent to, or for which the child is not developmentally prepared and cannot give consent, or that violates the laws or social taboos of society. Child sexual abuse is evidenced by this activity between a child and an adult or another child who by age or development is in a relationship of responsibility, trust or power, the activity being intended to gratify or satisfy the needs of the other person. This may include but is not limited to the inducement or coercion of a child to engage in any unlawful sexual activity; the exploitative use of a child in prostitution or other unlawful sexual practices and the exploitative use of children in pornographic performance and materials. (pp. 15-16)

The chapter is organised as follows. First we describe the context of youth and community work and young people's participation in CSE and CSA awareness and prevention in both countries and give a brief overview of each project. Methods and ethical principles for each of the studies are described and key findings presented. The conclusion confirms that interventions aimed at addressing violence and abuse can and should be situated in parallel to children and young people's (and their families') participation in these efforts. The community's acceptance, support and practice of this can foster a strength-based, empowering approach with regards to addressing child sexual abuse (Wallace, 2015).

\section{YOUTH AND COMMUNITY WORK}

The National Youth Association (2016) describes youth work as a process of enabling young people to improve selfbelief and life skills preparation. The foundation of traditional youth and community work is underpinned by informal education and a series of values that Jeffs and Smith (1999) described as respect, promotion of well-being, truth, democracy, fairness and equality. They viewed conversations and encounters as important vehicles for empowering young people. Youth work provision in England and Wales has been subject to a large range of financial cuts and restrictions since 2015, which have led to closures and reductions in provision. However, the principles of youth and community work remain intact and its qualities have huge potential for supporting children, young people and their families, and thereby increasing protective factors in the prevention of CSE. The authors observed these principles in operation in their research with children, young people and their families in the FCASE project discussed in this chapter.

Over the past decade a series of high-profile police operations, court cases and on-going investigations into the sexual exploitation of children and young people has drawn attention to the nature and extent of CSE in the UK as a form of abuse (Beckett et al., 2013; Jay, 2014). There is growing research and practice which focuses upon support for victims and prevention of CSE (D'Arcy et al., 2015); and on the prevention of abuse before it occurs (Beckett and Warrington, 2015). While there is evidence of a need to educate and involve children and young people in preventative processes (Bhana, 2008; Cody, 2015), their participation in public-health and 
other approaches to prevention in both the UK and South Africa has been insufficiently articulated and practised. This principle is further explored in the South African case study presented in this chapter.

'Taking part' is an essential component of youth work practice. The common goal of participation is to create opportunities for young people to be more involved. This involves moving away from situations where young people are recipients of services towards a situation where they are invited to express their views and make a meaningful contribution to activities and decisions. There is now growing consensus that CSA prevention and support approaches must run parallel with children and young people's empowerment and that children have the capacity to deal with matters pertaining to sexuality, power relations and cultural beliefs (Bhana, 2008). CSA affects children, families, communities and entire societies, and its prevention has been listed as a public health priority by WHO (Krug et al., 2002). Although South Africa has advanced legal and policy frameworks, CSA rates are high and efforts have failed to reduce the number of cases, address cultural factors or encourage greater disclosure. Despite the suggested benefits and calls for children and young people's participation in matters affecting their lives, children remain invisible in efforts to address the issue and there remains a general paucity of research focusing on their participation in both CSE and CSA prevention and support for victims (Wallace, 2015).

\section{THE UK STUDY - FAMILIES AND COMMUNITIES AGAINST CHILD SEXUAL EXPLOITATION}

In the UK, voluntary sector services have been key players in the prevention and support of CSE (Pearce, 2009; Scott and Skidmore, 2006). Barnardo's is one of the largest non-governmental organisation
(NGO) providers of CSE-related services and has for the past two decades been supporting children and young people affected by sexual exploitation.

The Families and Communities against Child Sexual Exploitation (FCASE) project emerged out of Barnardo's work with sexually exploited children and young people in the UK. The project was designed both to build on existing expertise and to address the gap in parental/carer support which had been identified. The aim of the project was to embed more effective practice in safeguarding children and young people, including those in foster care, from sexual exploitation, through harnessing the protective factors within a child's family and/ or foster home. The project emphasised the need for work with parents and carers as well as the child or young person in order for early signs of CSE to be identified, and for preventative strategies to be put in place. In doing so it aimed to support processes for the sharing of intelligence and the disruption of abuse.

FCASE was piloted in three sites, as a component of existing Barnardo's services which sit within existing local authority structures and processes for the safeguarding of children and young people. The project built on Barnardo's wider work with sexually exploited young people, with the unique feature of working with parents/carers. The FCASE programme therefore complemented and developed the national UK strategy in supporting CSE prevention by drawing on other areas of work, such as family group work, family conferencing, influencing and awareness-raising strategies.

The three key objectives of the FCASE project were to provide:

1 Awareness training to 1,800 professionals working with children and young people;

2 A six- to eight-week direct work programme with children, young people and their parents/ carers (this includes the introduction of FCASE, initial assessment and incorporation of additional materials); 
3 Support and information to representatives from different communities to develop understanding of CSE via 36 community events.

This chapter focuses upon the second aim, the six- to eight-week direct work programme and the voices of young people and their families who participated in the programme to highlight the importance of the educational, participatory process adopted by workers delivering programme. Data collection included interviews with children and young people and their families and their FCASE workers, focus group discussions with FCASE workers and drawing on a range of quantitative data. The research received ethical approval from the University of Bedfordshire and from Barnardo's.

\section{THE PARTICIPATORY APPROACHES TO CHILD PROTECTION (PACP) PROJECT - SOUTH AFRICA}

The Participatory Approaches to Child Protection (PACP) project was undertaken to explore children's participation and community-based approaches aimed at involving all stakeholders, as essential elements of a holistic and sustainable solution to addressing CSA. It sought to examine whether securing the awareness, commitment and participation of both adult stakeholders and children in protection planning and implementation could serve as a catalyst of change within a South African context. The study utilised several participatory approaches to uncover cultural beliefs and practices; gave children an opportunity to voice concerns and generate solutions, addressing events which affected their lives; and empowered a community to bring about change.

The study was designed as a participatory action research project to address CSA and was undertaken by Candice Wallace as part of a placement for the organisation Project Hope UK, a global health education and humanitarian assistance organisation which has implemented numerous initiatives within a township in South Africa as part of their Thoughtful Path Programme. The project involved five phases over five weeks that included the participation of children and young people, adult community stakeholders and government stakeholders (see below [p. 420] for a full description of these phases). It ended in a one-day reportback session to foster cross-generational sharing, the establishment and strengthening of community-based protection systems, and the development of a community action plan. The study utilised participatory methods which gave participants the opportunity to choose different methods to express themselves, including art, dance, poetry, short stories, debates, games and song. Methods for the study are described alongside the key findings since the principles of action research make methods an integral part of the change process.

As a researcher, Wallace was cognisant that there was a chance that some contributions/performances referred to real experiences of abuse, which would require heightened awareness throughout the project to ensure that appropriate support was available to participants and that strict ethical guidelines were followed. Participants were reminded at the beginning and end of each session about the need for and importance of confidentiality due to the sensitive subject matter, their age and the familiarity between some group members. Participants had the option of writing down things they did not wish to share with the wider group in notebooks provided, which could be later shared in a more secure and private setting. The ethical process for the project was one of continuous reflection and learning, with clear awareness of the possibility that a child could disclose an incident of CSA, and highlighted the need for local support in the event that this occurred. The study received ethical approval from Brunel University, London (UK). 
This study highlights the viability of an approach to strengthening children's protective environments, through recognising and valuing children as agents of change, establishing networks between key stakeholders, and encouraging community ownership and commitment to the sustainability of the initiative.

\section{FINDINGS FROM THE UK STUDY: A PROCESS OF EDUCATION AND EMPOWERMENT}

Ingram and Harris (2001) describe good youth work as a learning process whereby youth workers and young people come together voluntarily to form equal caring relationships that can identify young people's needs to enable them to gain autonomy and hence take control of their lives responsibly. Although these youth work principles did not explicitly inform the design of the FCASE model, they do underpin the ethos of the work carried out and we draw on these principles to analyse project findings.

In terms of a learning process, the direct work programme included a series of sessions for parents, covering: understanding and living with risk; what is CSE?; abusive relationships and grooming; the Internet and consent. Sessions for young people covered: relationships; risk; abusive relationships; grooming in relationships; consent, law and e-safety, and each one ended with a summary of learning

The project entailed voluntary engagement: although families were referred to the programme by a range of agencies, including schools, social workers and police, they chose whether to take part or not. The first step in the programme was to ask if families wanted to be involved. If they agreed, one worker would work with the parent or carer and another with the young person. The time-frame of the programme was six to eight weeks for most families, however for more complex situations the work lasted longer. Workers needed to engage young people and their parents in the programme, and flexibility in time and place (as well as the delivery of the programme) was an important factor. For example, parents and carers appreciated meetings being organised around their work responsibilities and other commitments. Consequently, most of the work with families and young people took place 'out of hours'. Workers focused meetings on the needs of the young person and their parents or carers. For one young man, work was undertaken in a van outside his home because that was the only way he was allowed to engage with FCASE. Workers also focused the learning programme on the needs of young people. There was certainly flexibility in terms of the materials used. For one young woman, aged 14, with a much younger learning age, a whole new set of resources were developed in consultation with the clinical supervisor. The new material involved creative and imaginative forms of play involving collage, drawing and use of the sand tray. For the purposes of the evaluation, the researcher observed a refresher session between this young woman and two FCASE workers and it was clear that the young woman had learnt and retained far more about staying safe than the FCASE workers could gauge during the actual sessions. Another example was where a worker adapted work for a young man on the autistic spectrum, making sure that sessions were more visual and asking him to create a poster summarising what he had learnt as an aide memoire for when the programme had finished.

A central focus of the project was the meeting of young people's needs. Some young people found it hard to focus on one thing at a time so the delivery of the programme work was fluid. This tended to be the case for most young people - all aspects of the programme were covered, but some areas might receive more attention than others depending on the young person's needs. Workers' previous experience in working with young people and CSE was clearly advantageous. 
The young man on the autistic spectrum praised the approach; he also commented on his relationship with his worker, which was described as helpful because the worker was not a teacher or a member of his family. The fact that the worker was not his social worker or teacher made a difference as they were viewed as independent, even though several FCASE workers were qualified social workers.

Social workers and teachers they teach you about outside life. The FCASE worker talks about stuff more close to home, outside life and inside life and everything. (Young person)

The approach of the workers demonstrated strong relational skills and high levels of engagement with families, which sometimes were surprising to young people themselves.

Everyone at school prefers younger teachers and feels younger workers understand young people better. (Young person)

However, the young person reflected that somehow they clicked with the FCASE worker and started to enjoy the discussions and going to McDonalds.

Other research has highlighted the importance of such skills in work relating to child sexual exploitation (Shuker, 2012). A number of the families had experienced severe trauma and high levels of harm before the FCASE referral and had, in their words, experienced poor responses from other agencies such as the police, social services and schools. This was contrasted with the support that they felt they received from FCASE:

FCASE was the only agency that has been consistent and done what they had said they would do. They were honest and kept in contact and returned your calls. (Parent)

In CAF meetings - we had been thinking we must be rubbish parents. (Parent)

The nature of the FCASE programme facilitated support for families and this was different to other services:

I can voice my fears. Social Care and Social Workers are concerned with procedure; they don't deal with $\mathrm{me}$ - if I am scared. (Carer)
The combination of voluntary engagement, flexibility and identifying young people's needs resulted in learning. The research found that young people commented positively on the FCASE programme and process, they could recall what they had learnt and made changes to their lifestyles. This reflects the goal of 'good youth work', described by Ingram and Harris as 'achieving the autonomy to take control of their lives in a responsible way' (2001: p. vii). The fact that parents and young people undertook a structured programme was found to be beneficial as family members were learning together about CSE and this made it easier to discuss subjects that are often challenging:

I used to feel on edge but now I feel much more confident. Now I know what is safe/unsafe, right and wrong so I can say no. But she also knows her mum is there to support her if things go wrong. I would not have realised this person was grooming - that is the word she used - and it shocked me, we did the same session and we were both able to discuss it afterwards. (Parent)

I don't complain about my curfew of 7pm, before I thought it was too early but now I realise $8 \mathrm{pm}$ is too late and I can still have fun and come in earlier. (Young person)

The UNCRC (1989) Article 12 states that when adults are making decisions that affect children, children have the right to say what they think should happen and have their opinions taken into account. The FCASE programme facilitated a rights-based approach as parents and carers were having conversations with their children and involving them in decisions. Parents and young people noted that this had reduced arguments in the house because it had opened lines of trust and communication. Parents and carers spoke about feeling confident that young people had been given vital information about keeping safe and also felt like they were being treated with respect:

This house has changed in the way we deal with teenage angst. If we feel angry, we leave it and go back when we've calmed down whereas previously it would get blown out of proportion. 
My son had lost even the language at home. He was taking street language into the home. He'd be rude. He has been told he is rude. Hearing this from an outside person has made a difference.

Barnardo's stabilises her and helps her along. [Name of young woman] comes to us now, she informs us of things that are happening. Before she was hiding things but now she has seen we are willing to talk about it.

Similarly, one young person summarised her learning as encompassing the following:

Types of abuse, how to avoid arguments, about internet safety ... and I learnt about myself.

In some cases the study found that both parents and carers and young people were expressing the same views:

We learnt how to deal with our differences. (Carer)

There is less arguing. (Young person)

It has stopped a lot of arguments. We feel more confident. (Carer)

We both learnt to stop and listen. (Young person)

We learnt how to communicate with each other. (Parent)

FCASE concentrated on the strengths of families, rather than what was lacking, leading to improved relationships at home:

We don't fight anymore. I have learnt a lot and it changes my life. I think there should be more services for mums and daughters ... it did help. All her stress was leaving and all mine so we didn't argue. (Parent)

Parents also commented on the improvements in relationships and how the information received had helped them feel equipped with understanding and respect for other family members. Parents explained how relations had improved:

I understand my daughter a little better now and we can all talk about things now things you don't like to talk about. (Parent)

It has improved our home life; we can see each other's opinions and respect them. It has helped the future of my daughter, my son-in-law, me and it extends to family and friends as you talk to them about things. (Parent)
In one case involving a single father using the service, outcomes included learning about internet controls and safety. He noted that this was the most 'prominent thing' and it 'was good to be able to talk to someone else about it, because I'm on my own and it's quite difficult for me to get my head around things, especially for girls'.

This strengths-based process enabled families to reach joint decisions about safeguarding, enabling young people to have a voice in decisions made about them. For example, in reaching agreement over daily routines, one parent was very pleased that her daughter now calls her when she is out and explains where she is and what time she will be back, whereas in the past she would go missing for several hours without contact.

Relationships also improved because FCASE focused on parent/carer strengths. A review (D'Arcy, unpublished; D' Arcy et al., 2015) which explored effective approaches to support the parents of adolescents who have been affected by CSE, suggested that an ideal model of support comprises of helping relationships based on voluntary participation and trust and engagement with young people in the design, delivery and evaluation of support and intervention; both are key principles of good youth work.

Parents/carers spoke of the way that FCASE support had reassured them about their parenting:

$$
\text { It helped with parenting. We feel happier now. }
$$

FCASE workers highlighted that the ability to build relationships in a short space of time is key to assessing strengths and enables workers to challenge a parent or carer without them feeling that they are being talked down to or judged.

A rights-based approach was also evident in the final closing meetings at the end of the programme where families sat down with workers and other professionals involved to plan action for the future. These meetings were really valued by young people, parents, carers and workers, as evidenced in the quotes below. Reflecting on this process in a 
focus group discussion, workers spoke of the opportunity to create a space where conflicts could be resolved and mutually supportive rules could be established. As a worker stated:

These are good for getting everyone into one room and putting it all up on to flip chart paper, and often parents/carers and young people realise that they have the same objectives. (Worker)

It is striking that this had often been the first opportunity for parents/carers and young people to do this.

They'd listen to us and take note of what we wanted as a family. (Parent)

I thought the Safer You meeting was good because it got me back into school, I was frustrated to not be attending school. At the Safer You meeting we talked about harm - I'd probably be in jail now if I hadn't done this programme. (Young person)

To conclude, there is clear evidence that the process of the FCASE model was underpinned by core youth and community principles and values. There was respect, equality and participation for the whole family. The FCASE approach was voluntary and families themselves chose to take part. The programme facilitated a process that was empowering for parents and their child, and as a result of FCASE they were able to take control of their lives together. The holistic mechanisms that brought about change in families also reduced risk behaviours, which supports our argument that community-level preventative work engages children, young people and adults as social actors, collaborators, researchers and change agents in the prevention of abuse and violence.

\section{FINDINGS FROM THE SOUTH AFRICA STUDY: A JOURNEY OF AWARENESS, EMPOWERMENT AND CHANGE}

Active and voluntary participation is a key element of the youth work process. It is a way of thinking and working that facilitates joint decision-making by young people and youth workers and promotes personal and social development. This intervention adopted a participatory action research (PAR) approach which involved collaborative research, education and action that is oriented towards social change. Kemmis and Wilkinson (1998) point to some important features of PAR, namely its ability to recognise actors as active agents working towards social action rather than passive subjects; encourage individuals to examine and challenge the role of larger social, political, economic and cultural conditions that shape their identities and actions; inevitably touch on the issues of power, domination and hegemony; as well as its reflexive nature as participants are encouraged to critically examine their own role. These features were embodied in the design of the study through its recognition of the role of children as social agents, encouraging their full participation in the study design, development of prevention strategies, analysis of the power of various actors in CSA, and the reflection of participants on the role they play in addressing CSA. Although the principles of youth work highlighted by Ingram and Harris (2001) did not guide the design of this study, a youth development lens was applied to the process of PAR and the elements of voluntary engagement, meeting young peoples' needs, and a learning process can also be seen in the findings.

The study was conducted in a township in West Rand District, Gauteng Province, South Africa, with an estimated 10,000 or more orphan and vulnerable children. The location was chosen following Project Hope UK's 2010 assessment, which indicated that the population composition reflected a 'microcosm' of a wider orphan and other vulnerable children context across South Africa and much of Sub-Saharan Africa. Access to the community was negotiated through Project Hope UK and formed part of a wider community-based child protection initiative. In line with the principles of PAR, the findings were used by Project Hope UK and the community 
to propose and initiate local-level changes, such as the establishment of a communitybased child rights and protection unit, and of a children's centre established as a safe space in a once-abandoned lot, as well as creating networks between key stakeholders to strengthen the community's response to CSA. The project was implemented in five phases:

Phase 1: A semi-structured focus group was held with an initial group of nine children aged 9-14, selected through volunteer convenience sampling, to gain insight and to pilot research techniques and materials, and to consult with children about the research project and gain their feedback. This assisted in informing the design of the study, allowing children to play a strategic role in the formation and selection of methods used.

Phase 2: A participatory session was held with 27 adult community stakeholders, including representatives from nongovernmental organisations, counsellors, community workers, teachers and parents, who received an open invitation to participate. This session allowed the participants to open dialogue between them about the issue of CSA, and establish collaborative relationships and support systems. It also provided insight about the community views, cultural beliefs, perception on actions to tackle CSA, participants' ideas on what is needed and limitations or obstacles to address the issue.

Phase 3: Four sessions were held with 28 children and young people, aged 9-17 years, in participatory activities designed to explore key topics. Children and young people were introduced to a range of participatory techniques and invited to make additional suggestions. Children were able to help shape the agenda, draw upon concrete real-life events, talk about complex and abstract issues, and to interpret social structures and relationships which affect their lives. Thus, participatory methods explored children's capacities, needs and interests from their own points of view rather than viewing them as vulnerable victims. By exploring children's concept of CSA the findings show numerous social constructs that exist within a child's world that cannot be ignored or overlooked and are a significant source for understanding and dealing with CSA. These included salient factors, beliefs and practices present within children's subculture and gender-based beliefs held by both boys and girls.

Phase 4: Data analysis was dynamic and recursive and occurred throughout the process through open reflection and dialogue with participants during the participatory sessions in Phase 3. Children were asked to explain their submissions, providing the researcher with their interpretation and thus avoiding misinterpretation (Hazel, 1996). Within all of the participatory sessions children were also given an opportunity to write their thoughts before offering spontaneous verbal answers, they were therefore able to take their time and ensure that the finished product was a true representation of their thoughts. A journal was also kept by the participants and the researcher to foster individual reflection and provide a forum for the continuous exploration of developing ideas throughout the study.

Phase 5: At the end of the participatory sessions with the children and young people, a one-day preliminary report-back session was held with the adult stakeholders from Phase 2, where the contributions of the child participants were displayed. The session was part of a four-day Child Sexual Abuse workshop under the PACP project involving the Child Protection Unit of the South African police and social workers, designed to complement the study and simultaneously build adult awareness and capacity on the subject of CSA. The report-back session provided an opportunity for adult stakeholders to review children's submissions, which provided a view of children's subculture to better inform prevention strategies, acknowledge children's capacities in proposing solutions, and highlight the importance of their participation in informing advocacy and action. Due to the date and time of the session, the children were unable to report directly to the community stakeholders. The session was 
helpful in ensuring the children's ideas were taken on board in community planning and were given the necessary support in prevention initiatives. This allowed the community stakeholders to recognise and value children's perspectives and actively nurture meaningful exchange between adults and children within the community. The children's suggestions and recommendations were all incorporated into the action plan developed by the adults and there was a commitment to establishing a children's ambassador group where the voices of children could always be included in and guide community initiatives so that they would continue to participate in matters which affect their lives.

The stakeholders discussed the contributions and recommendations of the children and young people, and made resolutions to act on some aspects through establishing community-based mechanisms to address CSA, continuing to create spaces for children's participation, and creating safe spaces through strengthening child protective environments. The session contributed to the formation of the Child Rights and Protection Unit, established under The Thoughtful Path programme, as well as a Children's Ambassador Group and an action plan for continued initiatives after the study, including those proposed by the children and young people. A member of the children's ambassador group will represent the group in community planning, and participate in the design, planning and implementation of future initiatives, to ensure the voices of children continue to be heard in matters affecting their lives. These sessions demonstrated the importance of grounding initiatives in local knowledge and experiences, and involving communities in the process.

\section{VOLUNTARY ENGAGEMENT}

Participation in all the above sessions was voluntary and invitation letters and consent forms, requiring consent by both parent and child, were sent to children, young people and adults, seeking their willingness to participate. Children and parents were allowed time to reflect on the project and were given opportunities to put questions to the researcher prior to making a decision on whether to participate. The sessions with children were held on Saturdays, which avoided disruption of school attendance. Additionally, participation was flexible, and children and young people chose whether they wanted to attend on any given day and for any number of sessions. On one occasion, four participants who were not issued invitation letters heard about the sessions and attended. Similarly, the adult sessions were held conveniently around the available times of the majority, which allowed for greater participation.

As highlighted by Langhout and Thomas (2010: 61), PAR can be broadly characterised as a theoretical standpoint and collaborative methodology which ensures that those who are involved in research have a voice. This was particularly important as often the voices of children remain unheard in defining issues which address them.

\section{I like that we were discussing and coming up with our own plans and that shows that it's a team not a crèche. (Young person)}

This method proved useful in capturing the voices of both children and community stakeholders when proposing solutions. The researcher drew on her own professional experience as a mediator and child/youth worker, which proved helpful in the sessions. The findings of the study were presented, incorporating children's pictures and excerpts from their written submissions. One such example is the below statement from a campaign message proposed by a young person:

As South Africans we must stand up [for] these children ... The situation is the problem a child's future is blocked. Children don't know what they can do or what they did to deserve this. South Africa's great people. We can help these children. Thank you!!! 
The sessions were fluid: participants were introduced to a range of methods and were encouraged to think about additional methods for expressing their feelings and ideas. This recognised the need to tune into children and young people's 'culture of communication' in order to reveal their knowledge (Clark, 2010). Young people were free to choose the type of participatory method that they were most comfortable with and felt would best communicate their views, thereby, as Holloway and Valentine noted (2000), allowing them to construct their views in their own terms. Participants were able to contribute to the design and conduct of the sessions, to break down power imbalances and feel comfortable and unrestricted with regard to sharing information. They decided whether they worked individually or in groups, and the composition of those groups. The researcher acted as a facilitator, introducing key topic areas for exploration, observing and navigating the discourse led by the participants, and stimulating further discussion when necessary.

Children and young people were eager to develop their ideas through whatever method they chose. As such, they created messages, through their various mediums, geared towards educating various stakeholders about CSA. This allowed participants to feel empowered and provided an opportunity for them to express their agency in addressing CSA. Consequently, participants spoke about organising a group to continue working on other CSA initiatives, for example, community marches and posters, as well as finding a way to share the presentations they created with other people, demonstrating child-led advocacy. Below is an example of a message from a child participant geared towards parents.

Have an open relationship with your child ... teach your child about the privacy of the body ... listen to your children when they try to tell you something and give much attention to your child so that they won't seek it anywhere else. (Young person)
Embedded in their presentations were bold mission statements and calls for the end of child abuse, displaying initiative and recognition of CSA as a social problem by expressing themselves on the issue and the need for its eradication. In reflecting on the project most participants saw it as a learning process essential to educating the community and children, as well as to empowering the community to address CSA.

It was great because I knew nothing about sexual abuse, this campaign has been more educational ... (Young person)

All these lessons taught me how to avoid CSA and how to prevent it. (Young person)

As a mother this information helped me a lot to know my kids better and to understand the consequences of abuse and what exactly is sexual abuse. (Community worker)

The design of the PACP project, which included a simultaneous programme for adult stakeholders, had a number of distinct advantages. Through increased knowledge of CSA, parents/carers could create safer environments for their children and take better measures towards preventing the occurrence of CSA in their homes and in the community. Additionally, the participation of both adults and children, as with FCASE, resulted in open discussions on decreasing the secrecy surrounding CSA and stimulating adultchild discussions about sexuality. While most of the adult participants were parents, only a couple were parents of the children participating in the initiative. This was due to the distance and hours of work, which made it hard to attend. In order to expand the reach of the benefits of the project to the parents of the participants, the community worker established relationships with some of the parents and knowledge was shared through informal methods where possible.

The PACP project utilised a rights-based approach by bridging children's right to protection and their right to participation, which are often treated as oppositional thereby limiting the scope and depth of opportunities for them to be heard in matters affecting 
children's lives (Moses, 2008). The study confirms that children, though often afforded little room to operate as independent actors, are willing to do so with some adult support where necessary. The findings support the need to establish further mechanisms to facilitate the participation of children in decisions affecting them.

The study also showed that children and young people's involvement in the process was an intervention in itself, where participants learned skills through guided participation and active engagement with conditions that facilitated empowerment as well as social change.

The best thing is to learn about CSA and learn about how you can manage problems facing you in life. (Young person)

I think the project was very pleasing and very specific about what happens around us. We must always get with things like these and tell the community about these kinds of effects/happenings in our environmental situation. The happy part was when we presented our own thoughts ... (Young person)

As they asserted their knowledge, the children and young people creatively built on strategies to protect themselves (Jewkes et al., 2005). At the end, they shared their desire to become advocates for themselves and others, in particular through expressing their agency and the importance of their participation.

We have to make adults understand that children can play a role in CSA ... children can talk to their own parents and guardians to show them how children could play a role in CSA. (Young person)

We must involve ourselves as children to take part in community programmes ... we have the responsibility to show interest and take part. (Young person)

A positive experience of participation can generate confidence and a belief among children and adults that they can make a difference, and may encourage them to become actively involved in their local community and beyond. The PACP project's unique and holistic approach involving collaboration between government agencies, community stakeholders and children in the development of child protection initiatives can provide meaningful and long-term protection for all children.

\begin{abstract}
Five years on, based on the evidence revealed through the research, practical and effective solutions to the challenges faced by children threatened by or experiencing abuse in the South African township have been developed to benefit thousands of children each year. (Director, Project Hope UK)
\end{abstract}

This supports our argument that securing the participation and empowerment of both adults and children as social actors in community-based protection planning and implementation can serve as a catalyst for change.

\section{CONCLUSION}

The two studies underscore the value of empowerment, participation and community approaches in addressing CSE and CSA. Together they contribute to a larger argument about the benefits of applying the principles of youth work in working with children and young people on sensitive topics. The effectiveness of these approaches in two very different contexts - a UK child protection framework, a South African communitybased systems strengthening approach - demonstrates the potential for these insights to be applicable in a variety of countries and contexts. Evidence from both of the programmes also points to the importance of taking youth work beyond the boundaries of working solely with children and young people and involving parents, carers, community members and other stakeholders in ethical, meaningful engagement.

The importance of ensuring that children and young people remain at the forefront of decision-making and planning along with family members and the community in a 
programme is demonstrated in the South African study, while the UK study highlights the benefits of children and young people learning together in a parallel programme with their parents or carers. It is useful to see these elements of the two studies as related points for practice which youth workers need to consider as part of a rights-based approach. We do not suggest one 'right' answer for practice but instead hope that the insights from these two studies point up dilemmas that need to be addressed in the design of programmes.

These two studies suggest some advantages of a voluntary, strengths-based approach in supporting children and young people and their parents/carers. These include:

- Clear educational value for young people, parents, carers and even the wider community;

- Improvements in family relations and consequently a reduction in risk;

- Knowledge and confidence about keeping safe;

- Improved self-awareness and self-esteem for parents/carers and young people.

This chapter reveals how practices that encourage joint participation of community stakeholders allows for the creation and strengthening of networks and the establishment of sustainable systems grounded within the community. This reinforces the need for a holistic approach involving children, young people, parents, the community and the government, all working together and playing a significant part in the prevention of CSA and CSE and in child protection to create safer environments.

\section{REFERENCES}

Barnardo's (2011) An Assessment into the Potential Savings from Barnardo's Interventions for Young People who have been Sexually Exploited, Ilford, Barnardo's.

Barnardo's (2012) Tackling Child Sexual Exploitation. Believe in Children: Helping Local Authorities to Develop Effective Responses, Ilford, Barnardo's.
Beckett, H. and Warrington, C. (2015) Making Justice Work, University of Bedfordshire.

Beckett, H., Brodie, I., Factor, F., Melrose, M., Pearce, J., Pitts, J., Shuker, J. and Warrington, C. (2013) 'It's Wrong ... But you Get Used to It': A Qualitative Study of Gang-associated Sexual Violence Towards, and Exploitation of, Young People in England, University of Bedfordshire.

Bhana, D. (2008) 'Beyond stigma? Young children's responses to HIV and AIDS' Culture, Health and Sexuality 10(7), pp. 725-738.

Clark, A. (2010) 'Young children as protagonists and the role of participatory, visual methods in engaging multiple perspectives' American Journal of Community Psychology 46(1-2), pp. 115-123.

Cody, C. (2015) 'Young people affected by sexual violence as change makers in prevention efforts: what are the opportunities and what are the risks'. Available at: https:// www.beds.ac.uk/_data/assets/pdf_file/ 0008/487106/FINAL-Participation-forPrevention-Colloquium-Report-Low-Res.pdf

D'Arcy, K. (unpublished) Families and Communities Against Child Sexual Exploitation (FCASE): Exploring Effective Approaches to Support the Parents of Adolescents Who have been Affected by CSE: Mapping and Reviewing the Literature, University of Bedfordshire.

D'Arcy, K., Dhaliwal, S., Thomas, R., Brodie, I. and Pearce, J. (2015) Families and Communities Against Child Sexual Exploitation (FCASE): Final Evaluation Report, University of Bedfordshire.

Department of Education (2017) Child Sexual Exploitation: Definition and Guide for Practitioners. Available at: https://www.gov.uk/ government/publications/child-sexualexploitation-definition-and-guide-forpractitioners

Hazel, N. (1996) 'Elicitation techniques with young people' Social Research 12, University of Surrey.

HIV/Aids Alliance (2008) Feel! Think! Act! A Guide to Interactive Drama for Sexual and Reproductive Health for Young People, Brighton, International HIV/Aids Alliance.

Holloway, S. and Valentine, G. (eds) (2000) Children's Geographies, London, Routledge. 
Ingram, G. and Harris, J. (2001) Delivering Good Youth Work: A Working Guide to Surviving and Thriving, Lyme Regis, Russell House Publishing.

Jago, S. with Pearce, J., Arocha, L., Brodie, I., Melrose, M. and Warrington, C. (2011) What's Going on to Safeguard Children and Young People from Sexual Exploitation?, University of Bedfordshire. Available at: http://uobrep.openrepository.com/uobrep/ bitstream/10547/315159/1/wgoreport2011121011.pdf

Jay, A. (2014) Independent Inquiry into Child Sexual Exploitation in Rotherham 19972013, Rotherham. Available at: http://www. rotherham.gov.uk/downloads/file/1407/ independent_inquiry_cse_in_rotherham

Jeffs, T. and Smith, M. (1999) Youth Work Practice, Palgrave Macmillan, Basingstoke, UK.

Jewkes, R., Penn-Kekana, L. and Rose-Junius, H. (2005) ' "If they rape me, I can't blame them": reflections on gender in the social context of child rape in South Africa and Namibia' Social Science and Medicine 61(8), pp. 1809-1820.

Jupp-Kina, V. K. (2010) 'Participant or protagonist? The impact of the personal on the development of children and young people's participation'. Doctoral thesis, Durham University. Available at Durham e-theses online: http://etheses.dur.ac.uk/452/

Kemmis, S. and Wilkinson, M. (1998) 'Participatory action research and the study of practice'. In Atweh, B., Kemmis, S. and Weeks, P. (eds.) Action Research in Practice: Partnership for Social Justice in Education, Thousand Oaks, CA, Sage, pp. 21-36.

Krug, E. G., Dahlberg, L. L., Mercy, J. A., Zwi, A. B. and Lozano, R. (2002) World Report on Violence and Health, Geneva, World Health Organization.

Langhout, R. D. and Thomas, E. (2010) 'Imagining participatory action research in collaboration with children: an introduction' American Journal of Community Psychology 46(1-2), pp. 60-66.

Moses, S. (2008) 'Children and participation in South Africa: an overview' International Journal of Children's Rights 16(3), pp. 327-342.
National Youth Association (2016) 'What is youth work?' http://www.nya.org.uk/careersyouth-work/what-is-youth-work/

Office of the Children's Commissioner (2013) 'Sex Without Consent, I Suppose that is Rape': How Young People in England Understand Sexual Consent. Available at: http:// cwasu.org/wp-content/uploads/2016/07/ CONSENT-REPORT-EXEC-SUM.pdf

Parents Against CSE (PACE)/Virtual College (2013) Are Parents in the Picture? Professional and Parental Perspectives of Child Sexual Exploitation, PACE, London.

Pearce, J. J. (2009) Young People and Sexual Exploitation: It Isn't Hidden, You Just Aren't Looking. London, Routledge Falmer.

Scott, S. and Skidmore, P. (2006) Reducing the Risk: Barnardo's Support for Sexually Exploited Young People. A Two-Year Evaluation. Ilford, Barnardo's.

Shuker, L. (2012) Evaluation of Barnardo's Safe Accommodation Project for Sexually Exploited and Trafficked Young People. University of Bedfordshire.

Smeaton, E. (2013) Working with Children and Young People Who Experience Running Away and Child Sexual Exploitation: An Evidence-based Guide for Practitioners. Available at: http://www.barnardos.org.uk/ resources/research_and_publications/workingwith-children-and-young-people-whoexperience-running-away-and-child-sexualexploitation-an-evidence-based-guide-forpractitioners/publication-view.jsp? pid= PUB-2300

UNCRC (1989) The United Convention on the Rights of the Child. Available at: https:// downloads.unicef.org.uk/wp-content/ uploads/2010/05/UNCRC_united_nations_ convention_on_the_rights_of_the_child. pdf?_ga=1.14580532.2052788703.149320 6543

Wallace, C. (2015) 'Unveiling child sexual abuse through participatory action research' Social and Economic Studies 64(1), pp. 13-36.

World Health Organization (WHO) (1999) Report of the Consultation on Child Abuse Prevention, Geneva, 29-31 March. Document WHO/HSC/PVI/99.1. 